\title{
Toward an Understanding of High Performance Pharmaceutical Policy Systems: A "Triple-A" Framework and Example Analysis
}

\author{
Steve Morgan ${ }^{*}, 1$ Jae Kennedy ${ }^{2}$, Katherine Boothe ${ }^{1}$, Meghan McMahon ${ }^{3}$, Diane Watson ${ }^{1}$ and \\ Elizabeth Roughead ${ }^{4}$
}

${ }^{1}$ University of British Columbia, Vancouver, Canada

${ }^{2}$ Washington State University, Spokane, USA

${ }^{3}$ University of Toronto, Toronto, Canada

${ }^{4}$ University of South Australia, Adelaide, Australia

\begin{abstract}
Drawing on international examples of published policy objectives for national pharmaceutical policies, we propose a framework for gauging system performance on the health-related goals of policy in the pharmaceutical sector. We review basic policy structures and performance indicators for the seven participating countries of the Commonwealth Fund"s 2007 International Health Policy Survey. We explore performance on three inter-related objectives that support overarching health goals: promoting the accessibility, appropriateness, and affordability of medicines. Indicators of performance along these dimensions are compared across countries and stratified by age, income and morbidity. Though no country appears uniformly strong in all areas, several appear to have done well to manage sometimes-difficult tensions in the pharmaceutical sector.
\end{abstract}

\section{INTRODUCTION}

While pharmaceuticals can improve the health of patients and help mitigate health-related inequities within a population, their rising prominence in health care systems is not without challenges. Changes in pharmaceutical innovation, promotion, utilization, and cost place pressures on policy makers tasked with balancing disparate policy objectives in this sector. The pursuit of high performance requires clarity of policy goals and objectives, awareness of policy instruments and options, and understanding of policy impacts and interactions. Drawing on international examples of published policy objectives for national pharmaceutical policies, we propose a framework for gauging system performance on the health-related goals of policy in the pharmaceutical sector. We review some preliminary evidence concerning system performance in the seven countries participating in the Commonwealth Fund 2007 International Health Policy Survey: Australia, Canada, Germany, the Netherlands, New Zealand, the United Kingdom (UK) and the United States (US) [1].

\section{Conceptual Framework}

Because the policy challenges in the pharmaceutical sector are many and complex, policy solutions are unlikely to lie in any single instrument. It is therefore advantageous to view pharmaceutical policy from a systems perspective. High performance in pharmaceutical policy systems will require coordination of multiple policy instruments to address interrelated objectives. Based on a review of policy statements found in World Health Organization guidelines $[2,3]$ and documents describing current or proposed national

*Address correspondence to this author at the University of British Columbia, Canada; E-mail: morgan@chspr.ubc.ca policy frameworks in Australia [4], Canada [5], New Zealand [6], and the UK [7], we propose a framework that defines the core goal, related objectives, and relevant policy instruments of a "pharmaceutical policy system" (Fig. 1).

Central Goal: The WHO states that "...the goals of [a] national drug policy should always be consistent with broader health objectives, and policy implementation should help to achieve those broader objectives" [3]. Placing health objectives at the centre of national pharmaceutical policy systems is not to deny the importance of possible goals with respect to economic development, science and technology policy. Some such goals are, in fact, consistent with the pursuit of "broader health objectives" to the extent, for example, that advances in science and technology enable health care systems to achieve health objectives with fewer resource requirements and/or to address previously unmet health needs. Other, more strictly economic goals related to national industrial policy in the pharmaceutical sector would fit a separate, parallel framework $[8,9]$.

There may be multiple health objectives in a country, but with health regarded as a fundamental human right by the United Nations [10], it seems reasonable to assume that the central, health-related goal for pharmaceutical policy is to protect and improve health. We further posit that this goal is likely to be important both in terms of the health of individuals and in terms of the health of populations; and that such improvements in individual and population health are desired for today and into the future. "Sustainable improvements in level and distribution of health" therefore are placed at the centre of our framework for pharmaceutical policy systems (Fig. 1).

Surrounding the health-related goal of this framework are three categories of inter-related pharmacare policy objec- 


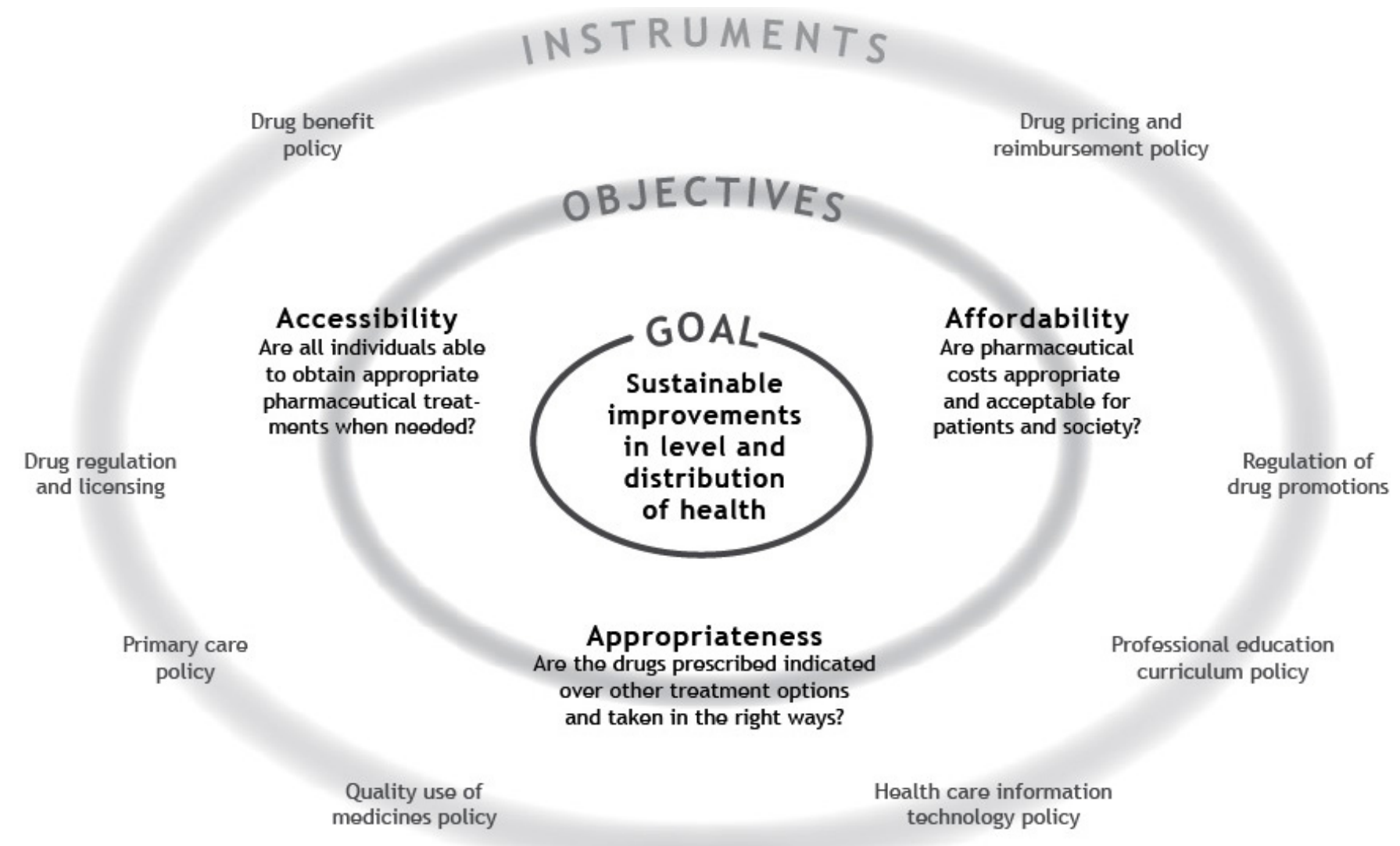

Fig. (1). The health-related goal, objectives and instruments of pharmaceutical policy systems.

tives: accessibility, appropriateness, and affordability of medicines used by a population. Objectives provide clearer, more measurable definitions of what needs to be obtained in order to have confidence that the system is contributing to the broader goal: the health of individuals and populations. The three objectives support and depend on each other, as success on one objective may depend on achievements related to another.

Accessibility: The accessibility of medically necessary treatments is a primary objective of pharmaceutical policy insofar as pharmaceuticals are first and foremost inputs into a broader system of care aimed at restoring or maintaining patient health. It is the notion of "medically necessary" that distinguishes pharmaceuticals from general commodities. Consumers would not knowingly seek pharmaceuticals unless they were experiencing ill health, or were at an elevated risk of falling into such a state. Demand for pharmaceuticals is therefore motivated by "needs" that may be (though some may not be) socially legitimized. Congruently, societies generally wish to ensure access to safe and effective pharmaceuticals when someone - regardless of age, income or health status - experiences a significant threat to, or deprivation of, good health.

Appropriateness: To obtain health-related goals in pharmaceutical policy requires appropriate use and selection of pharmaceuticals. Once again, pharmaceuticals are unlike ordinary commodities - this time, in the extent to which product selection and use may be regarded as a matter of policy concern due to health-, economic- or safety-related issues. Owing to potency, cost, and risks of serious adverse drug reactions, "more" medicine is not always "better". And while patient preferences over the potential health outcomes generated by treatment options are important, consumer preferences over the products themselves do not define whether drug use is appropriate. Appropriateness of use requires that a medicine be indicated - based on scientific evidence of comparative safety and effectiveness - for a given patient over other treatment options, including non-drug treatments. Appropriateness also requires correct dosing, minimized interactions with concomitant therapies, safe use of prescribed medicines, and adequate follow-up and monitoring of outcomes.

Affordability: The affordability of pharmaceutical costs borne by individuals and communities is a key policy objective as it relates to the overall equity and sustainability of pharmaceutical policy systems. Prescription drugs are unique goods in that patients often feel that they have little "choice" about consumption and that they "have" to find the means to purchase them $[11,12]$. Pharmaceutical use can therefore create financial burdens even if costs do not constitute a barrier to accessibility. Such burdens may create anxiety and even exacerbate income inequality, both of which can adversely affect health status. A pharmaceutical policy system should therefore strive to ensure that patient costs related to pharmaceutical needs are acceptable and equitable. Affordability must also be considered at the societal level to ensure system sustainability and that the best outcomes are achieved with available resources. It should be noted, therefore, that affordability considerations regarding (inappropriate) un- 
deruse of medicines would imply a need for greater resources for pharmaceuticals, potentially offset by reduced requirements in other components of the broader health care system.

Inter-Related Policy Instruments: A variety of policy instruments, such as those illustrated in the outer ellipse of Fig. (1), support one or more of the policy objectives. It is in this way that policies in this sector can be seen as interrelated components of a "system." The nature and extent of policy planning and coordination that occurs in a country can help to determine whether the many instruments related to pharmaceuticals serves as an integrated whole or whether certain policies generate logical inconsistencies.

The possibility of policy inconsistencies is important because, in a system, such inconsistencies do not exist solely in the failed implementation of a plan by a particular policy branch - such as failed implementation of a public awareness campaign related to appropriate use of antibiotics. Policy inconsistencies in policy systems can stem from conflicts between different policy instruments and the specific objectives being pursued by their use. To the extent, for example, that reimbursement policy (e.g., listing of medicines on a formulary) was to focus exclusively on affordability in terms of budgetary control, it may conflict with pursuit of accessibility through drug benefit program design.

In practical application, conflicts between policies are common and sometimes difficult to avoid. This is particularly true when responsibility for certain aspects of pharmaceutical policy rests with various branches of government or with other bodies to which responsibility has been ceded (e.g., professional colleges). However, conflicts can be managed to ensure the balance of impacts of varied policy instruments is likely to advance objectives in a way that service overarching goals. The establishment of coordinating mechanisms for pharmaceutical policies can help to achieve this, by weighing tradeoffs and helping to synchronize policy actions and instruments.

\section{METHODS}

For each system objective described above, we review basic policy structures and survey-based indicators of system performance for the seven countries participating in the Commonwealth Fund 2007 International Health Policy Survey. This review of instruments and indicators is to illustrate how key aspects of pharmaceutical policy systems can be examined and compared.

The Commonwealth Fund survey consisted of telephone interviews conducted between 6 March and 7 May 2007 with representative samples of 1,000 adults each in Australia and New Zealand; 1,500 adults each in Germany, the Netherlands, and the United Kingdom; 2,500 adults in the US; and 3,000 adults in Canada. Further survey details are provided elsewhere [1].

For each survey question analyzed below, individual responses were weighted to be representative of national populations. Chi-squared tests were conducted (using the SUDAAN 9.0 statistical software package for analysis of survey data) to determine whether differences in responses across countries were statistically significant. Similar tests were also conducted to identify statistically significant within- country differences across respondents of differing ages, incomes, or levels of chronic disease.

\section{RESULTS}

\section{Policies to Promote Accessibility}

Barriers to accessibility of necessary medicines are often financial in nature, caused by a lack of drug coverage or by cost-sharing rules applied to available coverage $[13,14]$. The extent of drug coverage offered in a country can therefore be described in terms of universality - the extent to which the entire population is covered; and comprehensiveness - the extent to which costs are borne by the collective financing mechanism rather than by the individual patient.

Publicly run programs provide universal drug coverage in Australia, New Zealand and the UK. Universal coverage is also attained in Germany and the Netherlands through social insurance mechanisms involving regulated competition. Pharmaceutical policy systems in the US and Canada are unique insofar as they offer non-universal mixes of public and private coverage. Public drug benefits in the US and Canada are generally targeted at select populations (e.g., the poor and the elderly); and private drug insurance is largely accessed through voluntary, employment-related benefits packages.

The degree to which coverage is considered comprehensive depends on deductibles, co-payments and patient contribution limits. While cost-sharing structures are complex within and across countries [15], co-payments are generally low for beneficiaries of drug plans across countries. Patient contributions in the Netherlands are negligible, limited only to surcharges for drugs priced above equivalent alternatives. In contrast, the AUS $\$ 30.70$ ( $\sim$ US $\$ 26.80$ ) faced by general beneficiaries in Australia during 2007 was a relatively high co-payment under national drug benefit programs studied. It is notable, however, that prescription charges in Australia and all other countries studied - are often reduced or waived for vulnerable populations (e.g., the elderly, social assistance recipients, chronically ill, etc.) and in some cases safety nets apply, such as an annual family cap on costs in Australia.

In contrast, several Canadian drug plans protect only against catastrophic drug costs by employing income-based deductibles or fixed thresholds after which public subsidies are provided [16]. Many drug plans in the US also employ specific deductible structures - the most peculiar of which is the "doughnut hole" in Medicare Part D [17]. Because of these coverage designs, Americans and Canadians with public drug benefits may receive less than "comprehensive" coverage.

\section{Accessibility Measures}

While ideal measures of access to necessary medicines might be specific to conditions and drug categories, overall prescription drug use and cost-related non-use provide preliminary indicators of accessibility. Shares of populations reporting prescription drug use ranged from 46 percent in Germany to 59 percent in the US (see Table 1). In all countries, pharmaceutical use was more frequently reported by older adults in comparison to younger adults, and by individuals with multiple chronic conditions in comparison with individuals without chronic disease. Known socio-economic 
Table 1. Indicators of Prescription Drug Accessibility

\begin{tabular}{|c|c|c|c|c|c|c|c|}
\hline & AUS & CAN & GER & NET & $\mathbf{N Z}$ & UK & US \\
\hline $\begin{array}{l}\text { How many prescription medications are you currently taking? } \\
\text { (\% reporting one or more) }\end{array}$ & $54.6^{\mathrm{a}}$ & $52.8^{\mathrm{a}}$ & $46.1^{\mathrm{a}}$ & $57.9^{\mathrm{a}}$ & $46.8^{\mathrm{a}}$ & $53.4^{\mathrm{a}}$ & $59.6^{\mathrm{a}}$ \\
\hline \multicolumn{8}{|l|}{ Age } \\
\hline $18-29$ & $29.6^{\mathrm{b}}$ & $32.9^{\mathrm{b}}$ & $24.3^{\mathrm{b}}$ & $42.8^{\mathrm{b}}$ & $40.5^{b}$ & $40.2^{b}$ & $39.2^{b}$ \\
\hline $65+$ & $91.0^{\mathrm{b}}$ & $85.9^{\mathrm{b}}$ & $77.6^{\mathrm{b}}$ & $86.5^{b}$ & $86.2^{\mathrm{b}}$ & $83.9^{b}$ & $86.8^{b}$ \\
\hline \multicolumn{8}{|l|}{ Chronic Conditions } \\
\hline 0 & $26.4^{\mathrm{b}}$ & $31.1^{\mathrm{b}}$ & $22.5^{\mathrm{b}}$ & $34.7^{\mathrm{b}}$ & $21.8^{\mathrm{b}}$ & $30.1^{\mathrm{b}}$ & $31.6^{\mathrm{b}}$ \\
\hline 1 & $61.6^{\mathrm{b}}$ & $63.6^{\mathrm{b}}$ & $61.6^{\mathrm{b}}$ & $78.3^{b}$ & $62.8^{\mathrm{b}}$ & $69.4^{\mathrm{b}}$ & $71.5^{b}$ \\
\hline below average & $69.1^{b}$ & $59.0^{\mathrm{b}}$ & 48.4 & $71.8^{\mathrm{b}}$ & $67.0^{\mathrm{b}}$ & $70.7^{b}$ & 60.3 \\
\hline Average & $53.9^{\mathrm{b}}$ & $51.1^{\mathrm{b}}$ & 49.3 & $59.7^{\mathrm{b}}$ & $43.6^{\mathrm{b}}$ & $52.8^{\mathrm{b}}$ & 57.6 \\
\hline above average & $42.1^{\mathrm{b}}$ & $49.3^{\mathrm{b}}$ & 42.1 & $48.9^{\mathrm{b}}$ & $38.7^{\mathrm{b}}$ & $40.9^{b}$ & 60.0 \\
\hline $\begin{array}{l}\text { During the past } 12 \text { months, was there a time when you did not } \\
\text { fill a prescription or skipped dose of medicine because of the } \\
\text { cost? (\% answering yes) }\end{array}$ & $13.4^{\mathrm{a}}$ & $8.0^{\mathrm{a}}$ & $11.5^{\mathrm{a}}$ & $2.0^{\mathrm{a}}$ & $10.0^{\mathrm{a}}$ & $5.4^{\mathrm{a}}$ & $23.1^{\mathrm{a}}$ \\
\hline \multicolumn{8}{|l|}{ Age } \\
\hline $18-29$ & $20.0^{\mathrm{b}}$ & $9.9^{\mathrm{b}}$ & $15.5^{\mathrm{b}}$ & 2.2 & $18.7^{\mathrm{b}}$ & $12.4^{\mathrm{b}}$ & $27.1^{b}$ \\
\hline $30-49$ & $15.7^{\mathrm{b}}$ & $8.8^{b}$ & $13.9^{\mathrm{b}}$ & 2.7 & $10.2^{b}$ & $5.7^{\mathrm{b}}$ & $27.1^{b}$ \\
\hline 2 or more & 15.2 & $12.0^{\mathrm{b}}$ & 11.2 & $4.0^{\mathrm{b}}$ & 10.4 & 5.1 & $29.5^{b}$ \\
\hline \multicolumn{8}{|l|}{ Income } \\
\hline below average & $19.3^{b}$ & $13.8^{\mathrm{b}}$ & 12.5 & 1.9 & $15.1^{\mathrm{b}}$ & 6.0 & $34.4^{\mathrm{b}}$ \\
\hline Average & $10.0^{\mathrm{b}}$ & $10.0^{\mathrm{b}}$ & 11.8 & 4.8 & $11.2^{\mathrm{b}}$ & 6.4 & $21.0^{\mathrm{b}}$ \\
\hline above average & $10.3^{b}$ & $4.0^{b}$ & 10.3 & 0.8 & $7.4^{\mathrm{b}}$ & 5.4 & $15.0^{b}$ \\
\hline
\end{tabular}

NOTE: AUS = Australia, CAN $=$ Canada, GER $=$ Germany, NET $=$ Netherlands, NZ = New Zealand, UK $=$ United Kingdom, and US $=$ United States .

NOTE: $\mathrm{a}=$ cross-national differences are significant at $\mathrm{p}=0.05$.

NOTE: $\mathrm{b}=$ intra-national differences by variable (e.g., age) are significant at $\mathrm{p}=0.05$.

SOURCE: Commonwealth Fund International Health Policy Survey, 2007

gradients in health status would suggest that medical needs will be highest amongst populations with relatively low incomes [18]. Consistent with this, individuals with belowaverage incomes reported using medicines more frequently than those with higher incomes in all countries except Germany and the US.

Most of the within-country differences in reported use of medicines suggest that pharmaceutical policies promote access to medicines among individuals with greatest need. However, non-use of prescription drugs due to financial considerations was far from zero everywhere but for the Netherlands and the UK. Americans were most likely (23 percent) to report skipping doses or failing to fill prescriptions due to costs. Australia also had a relatively high (13 percent) rate of reported cost-related non-use, possibly due to relatively high co-payment for general beneficiaries of Australia"s national prescription drug plan.

Within all countries, the elderly were less likely to report cost-related non-use of prescription drugs than younger adults. This suggests that age-based exemptions from copayments and/or age-based drug benefits (e.g., in the US and Canada) increase accessibility of medicines for the elderly relative to younger adults. Less encouraging is the fact that lower income populations were most likely to report cost- 
related non-adherence to treatment in Australia, Canada, New Zealand and the US.

\section{Policies to Promote Appropriateness}

Various policies are used to promote appropriate use of pharmaceuticals within and across the seven countries, but only Australia has identified the appropriate use of medicines as a central objective of its national policy framework [4]. The tools most commonly used to influence prescribing in the seven countries are formularies, continuing professional education, and guideline dissemination. Some countries, including Australia through its National Prescribing
Service and Canada through four provincial initiatives [19], have invested in academic detailing programs.

Policies targeted at patients tend to focus on the provision of plain language information regarding medicines, programs for specific communities (e.g., elderly), and telephone information services. Notably, while regulation of physiciantargeted drug promotion is varied but broadly comparable across countries, only New Zealand and the US permit direct-to-consumer advertising of prescription-only drugs [2026]. All countries except the US and Canada have moved toward (though none has yet fully implemented) universal

Table 2. Indicators of Prescription Drug Communication and Appropriateness

\begin{tabular}{|c|c|c|c|c|c|c|c|}
\hline & AUS & CAN & GER & NET & $\mathbf{N Z}$ & UK & US \\
\hline $\begin{array}{l}\text { In the past } 12 \text { months, has your regular doctor reviewed with you the } \\
\text { medications you take, including those prescribed by other doctors? } \\
\text { (\% of Rx users reporting yes) }\end{array}$ & $62.6^{\mathrm{a}}$ & $76.9^{\mathrm{a}}$ & $66.2^{\mathrm{a}}$ & $44.1^{\mathrm{a}}$ & $58.0^{\mathrm{a}}$ & $68.1^{\mathrm{a}}$ & $78.7^{\mathrm{a}}$ \\
\hline \multicolumn{8}{|l|}{ Age } \\
\hline $18-29$ & 74.1 & $66.2^{b}$ & 59.8 & 51.1 & 52.4 & 63.5 & $74.4^{b}$ \\
\hline $30-49$ & 59.1 & $75.1^{\mathrm{b}}$ & 64.8 & 37.5 & 64.8 & 68.0 & $73.3^{b}$ \\
\hline $50-64$ & 68.5 & $80.3^{b}$ & 67.2 & 45.8 & 59.6 & 75.5 & $82.0^{\mathrm{b}}$ \\
\hline $65+$ & 56.2 & $80.9^{b}$ & 68.6 & 48.5 & 54.5 & 64.7 & $84.3^{b}$ \\
\hline \multicolumn{8}{|l|}{ Chronic Conditions } \\
\hline 0 & 51.9 & $71.8^{b}$ & $59.0^{\mathrm{b}}$ & $33.7^{\mathrm{b}}$ & 52.4 & $61.3^{b}$ & $64.8^{b}$ \\
\hline 1 & 70.9 & $75.1^{\mathrm{b}}$ & $65.8^{\mathrm{b}}$ & $41.8^{\mathrm{b}}$ & 56.1 & $65.3^{\mathrm{b}}$ & $81.0^{\mathrm{b}}$ \\
\hline 2 or more & 62.5 & $81.5^{\mathrm{b}}$ & $71.4^{\mathrm{b}}$ & $56.6^{\mathrm{b}}$ & 64.2 & $76.6^{\mathrm{b}}$ & $84.3^{b}$ \\
\hline \multicolumn{8}{|l|}{ Income } \\
\hline below average & 61.8 & 77.7 & 67.8 & 38.1 & 55.9 & 72.2 & 79.8 \\
\hline Average & 65.7 & 76.6 & 67.4 & 48.1 & 54.0 & 64.0 & 77.5 \\
\hline above average & 62.0 & 77.2 & 65.7 & 46.5 & 62.9 & 68.6 & 77.8 \\
\hline $\begin{array}{l}\text { In the past } 2 \text { years, have you ever been given the wrong medication or } \\
\text { wrong dose when filling a prescription or while hospitalized? (\% reporting } \\
\text { yes) }\end{array}$ & 8.1 & 5.9 & 5.2 & 6.2 & 6.3 & 5.6 & 7.2 \\
\hline \multicolumn{8}{|l|}{ Age } \\
\hline $18-29$ & 8.6 & 7.7 & 7.0 & 7.1 & 7.7 & 7.2 & $11.2^{\mathrm{b}}$ \\
\hline $30-49$ & 8.3 & 5.7 & 4.2 & 5.3 & 6.6 & 6.3 & $5.5^{\mathrm{b}}$ \\
\hline $50-64$ & 5.8 & 5.7 & 4.2 & 5.4 & 5.8 & 4.5 & $8.0^{\mathrm{b}}$ \\
\hline $65+$ & 9.8 & 4.5 & 6.5 & 8.9 & 4.0 & 3.7 & $4.5^{\mathrm{b}}$ \\
\hline \multicolumn{8}{|l|}{ Chronic Conditions } \\
\hline 0 & $4.7^{b}$ & $3.3^{\mathrm{b}}$ & 4.1 & $3.5^{\mathrm{b}}$ & $4.0^{\mathrm{b}}$ & $3.0^{\mathrm{b}}$ & $3.5^{\mathrm{b}}$ \\
\hline 1 & $8.3^{b}$ & $6.9^{\mathrm{b}}$ & 5.7 & $7.2^{\mathrm{b}}$ & $8.8^{\mathrm{b}}$ & $5.3^{\mathrm{b}}$ & $7.7^{\mathrm{b}}$ \\
\hline 2 or more & $12.7^{\mathrm{b}}$ & $10.3^{b}$ & 7.3 & $12.6^{\mathrm{b}}$ & $7.9^{\mathrm{b}}$ & $13.0^{\mathrm{b}}$ & $12.0^{\mathrm{b}}$ \\
\hline \multicolumn{8}{|l|}{ Income } \\
\hline below average & $13.4^{\mathrm{b}}$ & 6.6 & 6.3 & 7.7 & 4.5 & 7.6 & 7.2 \\
\hline average & $5.2^{\mathrm{b}}$ & 4.7 & 3.7 & 6.8 & 6.2 & 4.4 & 6.0 \\
\hline above average & $4.9^{\mathrm{b}}$ & 5.6 & 5.3 & 5.1 & 6.8 & 5.7 & 7.4 \\
\hline
\end{tabular}

NOTE: AUS $=$ Australia, CAN $=$ Canada, GER $=$ Germany, NET $=$ Netherlands, $\mathrm{NZ}=$ New Zealand, $\mathrm{UK}=$ United Kingdom, and US $=$ United States

NOTE: $\mathrm{a}=$ cross-national differences are significant at $\mathrm{p}=0.05$.

NOTE: $\mathrm{b}=$ intra-national differences by variable (e.g., age) are significant at $\mathrm{p}=0.05$.

SOURCE: Commonwealth Fund International Health Policy Survey, 2007. 
electronic prescribing and information support systems [2731]. Eighty percent or more of physicians in Australia, Netherlands, New Zealand, and the UK routinely accessed electronic patient information systems that could flag potential problems with drug doses or interactions [32]. In contrast, 40 percent of German physicians, 23 percent of American physicians, and only 10 percent of Canadian physicians had routine access to such systems.

\section{Appropriateness Measures}

Appropriate use of medicines is an area of pharmaceutical policy requiring much improvement in measurement and monitoring. Limited aspects of appropriate use of pharmaceuticals can be gauged from patient-reported communications and errors related to medicines (see Table 2). The percentage of survey respondents reporting that their primary care doctor had reviewed their medicines with them in the past year ranged from 44 percent in the Netherlands to 78 percent in the US. Communication was relatively high in the US and Canada (77 percent); and in both of these countries the elderly - who most frequently use prescription drugs were most likely to report communication about drugs prescribed. That patients report reviewing medicines with doctors more frequently in the US and Canada may be due to the fact that primary care practices in these countries are far less likely to have access to information systems that would automatically provide them with such information [32].

Patient-reported prescribing error did not differ significantly across countries, ranging from 5.2 percent in Germany to 8.1 percent in Australia. In all seven countries, persons with multiple chronic conditions were more likely to report a prescribing error than those with one or no chronic conditions. This most likely reflects the fact that persons with chronic conditions use more prescriptions than others.

\section{Policies to Promote Affordability}

The equity and acceptability of financial burdens at the patient level is promoted through specific limits on patient contributions under drug benefit plans. Patients' out-ofpocket costs are capped or subsidy rates increased at given thresholds in most countries. There are no such caps in the Netherlands; however, patient contributions per prescription are negligible in that country [33]. Out-of-pocket costs are not capped under many private and public drug plans operating in the US and Canada [34-36].

Policies to support affordability of medicines at the community or national level take a variety of forms across countries. Various forms of price determination, such as reference pricing or tiered formularies, are common expenditure management tools. Private drug plans in the US, for example, often use "preferred" formulary listings, which set co-payments for a given product lower than for competitors within the same drug class, as a tool in price negotiations with manufacturers $[37,38]$. Though tiered co-payments are seldom found outside the US, reference pricing is a comparable policy tool in other countries. Germany, for example, uses an extensive system of reference pricing that limits reimbursement prices for drugs within groupings with similar chemical and/or therapeutic properties [39]. Reference pricing is also widely used when determining formulary listings in Australia, New Zealand, and the Netherlands; it is also used, to a limited extent, in some Canadian provinces.

Some countries have developed incentives for physicians to consider drug costs while prescribing. For example, at various points in the 1990s, drug budgets for German sickness funds were capped, with overruns drawn from budgets for physicians' remuneration [40]. Similarly, also in the 1990 s, primary care practices in the UK were given the option to hold fixed budgets to cover their patients" primary care and pharmaceutical needs; such budgets, and related incentives, are now held by larger Primary Care Trusts under the policy of practice-based commissioning [41, 42]. District Health Boards in New Zealand also fund pharmaceutical expenditures out of broader health services budgets. New Zealand is distinct in that its District Health Boards have centralized the drug formulary management at the national level and set annual District budget targets for drug expenditures $[43,44]$.

\section{Affordability Measures}

An indicator of equity in financial burdens at the individual level is out-of-pocket costs (see Table 3). Approximately 13 percent of Americans reported out-of-pocket costs exceeding US $\$ 1,000$, while approximately 1 percent of the populations in the UK and the Netherlands exceeded the threshold. There are no statistically significant differences in out-of-pocket costs across age, disease status, or income groups in the UK and the Netherlands. Other countries appear to have more variation in financial burdens across these groups. The elderly were more likely to report high out-ofpocket costs only in the US and Canada. Those with a greater number of chronic conditions were also more likely to report high out-of-pocket costs in the US, Canada and Germany. Lower income populations were less likely to report high out-of-pocket costs in Australia and Germany.

System-level affordability can be gauged by considering the rate of growth for pharmaceutical expenditure in relation to health care expenditure and national income. For each of the seven countries, Table 4 lists average annual growth rates during the period 1995 to 2005 for per capita pharmaceutical expenditure (prescription and non-prescription combined), health care expenditure, and gross domestic product (GDP). Figures are adjusted for general inflation in each country. Growth in pharmaceutical expenditure per capita generally exceeded growth in health expenditure and GDP within countries. Spending on medicines grew at the slowest rate in New Zealand (2.5 percent per annum). Germany had the next slowest growing expenditure on pharmaceuticals, at 3.5 percent per annum during this era. The relatively slow growth in New Zealand and Germany over this period may reflect the impact of budget caps - although caps were introduced in very different ways in the two countries. Per capita pharmaceutical expenditures grew fastest in the US (7.1 percent per annum) during this period.

\section{LIMITATIONS}

We use the terms "toward" and "understanding" in our title to recognize that (1) a detailed review of policies for health systems [1] or pharmaceutical sectors [45, 46] in seven countries is not possible in a single paper; and (2) that 
Table 3. Indicators of Prescription Drug Affordability

\begin{tabular}{|c|c|c|c|c|c|c|c|}
\hline & AUS & CAN & GER & NET & $\mathbf{N Z}$ & UK & US \\
\hline $\begin{array}{l}\text { In the past } 12 \text { months, how much have you and your family spent out of } \\
\text { pocket on prescription medications? (\% reporting US } \$ 1000 \text { or more) }\end{array}$ & $5.3^{\mathrm{a}}$ & $5.7^{\mathrm{a}}$ & $2.8^{\mathrm{a}}$ & $0.9^{\mathrm{a}}$ & $2.4^{\mathrm{a}}$ & $1.2^{\mathrm{a}}$ & $13.2^{\mathrm{a}}$ \\
\hline \multicolumn{8}{|l|}{ Age } \\
\hline $18-29$ & $6.6^{\mathrm{b}}$ & $2.5^{\mathrm{b}}$ & 2.4 & 3.9 & 2.6 & 1.7 & $6.3^{b}$ \\
\hline $30-49$ & $4.6^{\mathrm{b}}$ & $4.4^{\mathrm{b}}$ & 2.0 & 0.4 & 3.2 & 1.4 & $10.8^{\mathrm{b}}$ \\
\hline $50-64$ & $8.1^{\mathrm{b}}$ & $9.3^{\mathrm{b}}$ & 2.7 & 0.5 & 1.8 & 1.3 & $18.2^{\mathrm{b}}$ \\
\hline $65+$ & $1.9^{\mathrm{b}}$ & $8.6^{\mathrm{b}}$ & 5.2 & 0.3 & 0.6 & 0.4 & $21.4^{\mathrm{b}}$ \\
\hline \multicolumn{8}{|l|}{ Chronic Conditions } \\
\hline 0 & 4.5 & $2.9^{\mathrm{b}}$ & $1.9^{\mathrm{b}}$ & 1.4 & 1.2 & 1.0 & $7.4^{\mathrm{b}}$ \\
\hline 1 & 6.7 & $4.7^{\mathrm{b}}$ & $1.9^{\mathrm{b}}$ & 0.2 & 3.1 & 0.8 & $13.4^{\mathrm{b}}$ \\
\hline 2 or more & 5.3 & $12.4^{\mathrm{b}}$ & $6.4^{\mathrm{b}}$ & 0.4 & 4.7 & 2.3 & $21.5^{\mathrm{b}}$ \\
\hline \multicolumn{8}{|l|}{ Income } \\
\hline below average & $2.3^{\mathrm{b}}$ & 5.5 & $1.1^{\mathrm{b}}$ & 0.0 & $2.7^{\mathrm{b}}$ & 0.7 & 12.5 \\
\hline average & $3.6^{\mathrm{b}}$ & 7.7 & $1.4^{\mathrm{b}}$ & 0.0 & $0.4^{\mathrm{b}}$ & 0.3 & 13.5 \\
\hline above average & $7.8^{\mathrm{b}}$ & 4.8 & $4.5^{\mathrm{b}}$ & 1.7 & $3.1^{\mathrm{b}}$ & 1.9 & 13.6 \\
\hline
\end{tabular}

NOTE: AUS = Australia, CAN $=$ Canada, GER = Germany, NET $=$ Netherlands, NZ = New Zealand, UK = United Kingdom, and US = United States.

NOTE: $\mathrm{a}=$ cross-national differences are significant at $\mathrm{p}=0.05$.

NOTE: $\mathrm{b}=$ intra-national differences by variable (e.g., age) are significant at $\mathrm{p}=0.05$.

SOURCE: Commonwealth Fund International Health Policy Survey, 2007

comparable indicators of pharmaceutical policy performance are very scarce, representing an area of much needed development. The Commonwealth Fund survey provides an opportunity to compare and contrast an accessible though admittedly imperfect set of comparable indicators of pharmaceutical policy outcomes. We hope this review will encourage more concerted, cross-national efforts to define, measure, and monitor system performance in the pharmaceutical sector.

\section{CONCLUSIONS}

The purpose of proposing a systems framework for pharmaceutical policy, and for reviewing related results of the Commonwealth Fund survey, was to stimulate discussion and activities in the area of comparative analysis of pharmaceutical policy systems. Based on our review of related international documents, we believe that such analyses should be situated within the context of health-related goals and objectives. Because of the increasing prominence of pharmaceuticals in health care systems, we also note that an increasing number of countries have adopted or are developing national processes for coordinating various policy actions in this domain. This suggests that pharmaceutical policy might best be viewed from a systems perspective, with multiple policy instruments interacting in pursuit of policy goals and objectives.

In light of the complexity of pharmaceutical policy systems, and of the inescapable reality that public policy (in this as in other domains) is the art of balancing often-competing claims and objectives, we did not expect nor observe identical policy approaches across the countries reviewed. Some cross-national variation in pharmaceutical policy - including deviations from what we might consider "ideal" - will be due to different priorities for and interpretations of healthrelated objectives. Other variations will be due to differences in the weight placed on non-health related goals, such as industrial development. Finally, some cross-national variation will be due to real differences in performance that result from policy coordination and/or experimentation within given countries.

Table 4. Inflation-Adjusted Growth in Per Capita Pharmaceutical Spending, Health Care Spending and National Income, 1995 to 2005

\begin{tabular}{|c|c|c|c|}
\hline \multirow{2}{*}{} & \multicolumn{3}{|c|}{ 1995-2005 } \\
\cline { 2 - 4 } & Rx & HC & GDP \\
\hline \hline Australia & 6.3 & 4.5 & 2.4 \\
\hline Canada & 5.8 & 3.2 & 2.3 \\
\hline Germany & 3.5 & 1.8 & 1.2 \\
\hline Netherlands & 4.3 & 3.3 & 2.0 \\
\hline New Zealand & 2.5 & 4.2 & 1.9 \\
\hline United Kingdom & 5.6 & 4.2 & 2.4 \\
\hline United States & 7.1 & 3.6 & 2.2 \\
\hline Average & 5.0 & 3.6 & 2.1 \\
\hline
\end{tabular}

NOTE: $\mathrm{Rx}=$ pharmaceutical expenditure; $\mathrm{HC}=$ health care expenditure; and GDP $=$ gross domestic product.

SOURCE: Authors" calculations based on OECD Health Data 2007: Statistics and Indicators for 30 Countries www.oecd.org/health/healthdata, and NHS Information Centre, "Prescriptions Dispensed in the Community 1996-2006 [NS]," 2007, http://www.ic.nhs.uk/.

Universal frameworks for providing drug coverage generally appear to result in improved access to medicines. 
These also appear to be enabling policies for promoting affordability at the individual and national level. The latter policy interaction may stem from the ability of drug benefit providers to set terms of coverage, including "what" is covered and the "price" that it will be paid. Experiences in the US and Canada - where systems do not currently provide universal coverage for all members of the population - illustrate the potential drawbacks of non-universal frameworks for providing drug coverage. While access measures suggest that elderly Americans and Canadians are able to obtain prescribed medicines, affordability measures suggest that they face sometimes-significant financial burdens associated with their health needs. Moreover, despite the lack of universal coverage in the US and Canada, or perhaps because of this feature of those systems, both countries have experienced relatively high pharmaceutical cost growth.

A notable policy paradox is found in the case of Australia. The Australian Pharmaceutical Benefits Scheme is a long-standing universal public program with a relatively comprehensive benefit list. Over its history, however, copayments under this Australian system may have increased to a point where they are hindering goals with respect to patient affordability of medicines. At the very least, this is a hypothesis worthy of further investigation. We also note that the Commonwealth Fund survey data suggest that the Australian public is more acutely aware of or concerned about prescribing appropriateness than populations in the other countries studied. This may reflect an increased salience of related issues in the Australian context somewhat ironically because Australia has a national strategy for promoting quality use of medicines.

High performing pharmaceutical policy is desirable for a number of reasons, but first and foremost to ensure good health. Because of the complexity and interdependence of various policy goals in this sector, high performing systems may be those making concerted efforts to coordinate and integrate policy actions. Cross-national policy comparisons and learning can facilitate the development of such systems. But to advance policy in this important sector will require more concerted efforts to define, measure, and monitor national performance of pharmaceutical policy systems. This is going to require international collaboration on the collection of reliable measures of performance along the multiple dimensions of pharmaceutical policy system performance. The dimensions of accessibility, appropriateness and affordability of medicines used by populations may be an appropriate place to focus such efforts.

\section{ACKNOWLEDGEMENT}

This project was supported, in part, by The Commonwealth Fund, a New York City-based private independent foundation. The views presented here are those of the authors and not necessarily those of The Commonwealth Fund, its directors, officers, or staff. Steve Morgan is supported, in part, by career awards from the Canadian Institutes of Health Research and the Michael Smith Foundation for Health Research.

\section{REFERENCES}

[1] Schoen C, Osborn R, Doty MM, Bishop M, Peugh J, Murukutla N. Toward higher-performance health systems: Adults' health care experiences in seven countries, 2007. Health Affairs (Millwood) 2007; 26(6): 717-34.

[2] World Health Organization. Guidelines for developing national drug policies. Geneva: World Health Organization 1988.

[3] World Health Organization. How to develop and implement a national drug policy. $2^{\text {nd }}$ ed. Geneva: World Health Organization 2001.

[4] Commonwealth Department of Health and Aged Care. National Medicines Policy 2000. Canberra: Commonwealth Department of Health and Aged Care 1999.

[5] First Ministers Task Force on the National Pharmaceuticals Strategy. National Pharmaceuticals Strategy Progress Report. Ottawa, Ontario: Health Canada; 2006.

[6] Ministry of Health. Towards a New Zealand Medicines Strategy: Consultation document. Wellington: New Zealand Ministry of Health December 2006.

[7] Walley T, Earl-Slater A, Haycox A, Bagust A. An integrated national pharmaceutical policy for the United Kingdom? BMJ 2000; 321(7275):1523-6

[8] Jacobzone S. Pharmaceutical policies in OECD countries : reconciling social and industrial goals. OECD working papers. Paris, France: Organization for Economic Co-operation and Development 2000; Report No.: v. 8, no. 23.

[9] Morgan S, McMahon M, Greyson D. Balancing health and industrial policy objectives in the pharmaceutical sector: lessons from Australia. Health Policy 2008; 87(2): 133-45.

[10] United Nations. International Covenant on Economic, Social and Cultural Rights. In. Geneva: United Nations Office of the High Commissioner for Human Rights 1966.

[11] Britten N. Patients' ideas about medicines: a qualitative study in a general practice population. Br J Gen Pract 1994; 44(387): 465-68.

[12] Doran E, Robertson J, Henry D. Moral hazard and prescription medicine use in Australia-the patient perspective. Soc Sci Med 2005; 60(7): 1437-43.

[13] Soumerai SB, Ross-Degnan D, Fortess EE, Abelson J. A critical analysis of studies of state drug reimbursement policies: research in need of discipline. Milbank Q 1993; 71(2): 217-52.

[14] Adams AS, Soumerai SB, Ross-Degnan D. The case for a medicare drug coverage benefit: a critical review of the empirical evidence. Annu Rev Publ Health 2001; 22: 49-61.

[15] Noyce PR, Huttin C, Atella V, et al. The cost of prescription medicines to patients. Health Policy 2000; 52(2): 129-45.

[16] CIHI. Drug expenditure in Canada 1985-2006. Ottawa: Canadian Institute for Health Information May 2007.

[17] Department of Health and Human Services. Medicare \& You 2008. 2007 [cited 2007 December 12]; Available from: http://www.medicare.gov/publications/pubs/pdf/10050.pdf

[18] Wilkinson RG. Socioeconomic determinants of health: Health inequalities: relative or absolute material standards? BMJ 1997; 314(7080): 591-5.

[19] Kondro W. Academic drug detailing: an evidence-based alternative. CMAJ 2007; 176(4): 429-31.

[20] Kaplan HL, Strongman JA. Pharmaceutical Advertising 2007: USA. The International Comparative Legal Guide to: Pharmaceutical Advertising 2007. London: Global Legal Group 2007; pp. 33441.

[21] Cameron N, Stubbs P. Pharmaceutical Advertising 2007: New Zealand. The International Comparative Legal Guide to: Pharmaceutical Advertising 2007. London: Global Legal Group 2007; pp. 247-55.

[22] Poelmann-Teijgeler S, Hustinx JP. Pharmaceutical Advertising 2007: Netherlands. The International Comparative Legal Guide to: Pharmaceutical Advertising 2007. London: Global Legal Group 2007; pp. 240-6.

[23] Dieners P, Klümper M. Pharmaceutical Advertising 2007: Germany. The International Comparative Legal Guide to: Pharmaceutical Advertising 2007. London: Global Legal Group 2007; pp. $140-8$.

[24] Bore J, Valverde S. Pharmaceutical Advertising 2007: England \& Wales. The International Comparative Legal Guide to: Pharmaceutical Advertising 2007. London: Global Legal Group 2007; pp. $110-8$.

[25] Hearn B, Wakulowsky L. Pharmaceutical Advertising 2007: Canada. The International Comparative Legal Guide to: Pharmaceutical Advertising 2007. London: Global Legal Group 2007; pp. 63-72. 
[26] Loveday C, Williams G. Pharmaceutical Advertising 2007: Australia. The International Comparative Legal Guide to: Pharmaceutical Advertising 2007. London: Global Legal Group 2007; pp. 31-8.

[27] McInnes DK, Saltman DC, Kidd MR. General practitioners' use of computers for prescribing and electronic health records: results from a national survey. Med J Australia 2006; 185(2): 88-91.

[28] Boonstra A, Boddy D, Fischbacher M. The limited acceptance of an electronic prescription system by general practitioners: reasons and practical implications. New Technol Work Employ 2004; 19(2): 128-44.

[29] NHS Connecting for Health. Electronic Prescription Service (EPS). 2007 Wednesday, 19 September 2007 [cited 2007 December 4]; Available from: http://www.connectingforhealth.nhs.uk/systems andservices/eps

[30] Hammond B. Electronic prescribing - developing the solution. Hospital Pharmacist 2007; 14: 221-4.

[31] Federal Ministry of Health. The Electronic Health Card. Berlin: Federal Ministry of Health, Public Relations Section; 2006.

[32] Schoen C, Osborn R, Huynh PT, Doty M, Peugh J, Zapert K. On the front lines of care: primary care doctors' office systems, experiences, and views in seven countries. Health Aff (Millwood) 2006; 25(6): w555-71.

[33] de Wolf P, Brouwer WB, Rutten FF. Regulating the Dutch pharmaceutical market: improving efficiency or controlling costs? Int J Health Plann Manag 2005; 20(4): 351.

[34] Coombes M, Morgan S, Barer ML, Pagliccia N. Who's the fairest of them all? Which provincial pharmacare model would best Protect Canadians against catastrophic drug costs? Longwoods Review 2004; 2(3): 13-26.

[35] Joyce GF, Goldman DP, Karaca-Mandic P, Zheng Y. Pharmacy benefit caps and the chronically Ill. Health Aff (Millwood) 2007; 26(5): 1333-44.
[36] Canadian life and health insurance association Inc. A guide to supplementary health insurance. 2006 [cited 2007 December 12]; Available from: http://www.clhia.ca/download/Health_Brochure_ EN.pdf

[37] Malkin JD, Goldman DP, Joyce GF. The changing face of pharmacy benefit design. Health Affairs (Millwood) 2004; 23(1): 1949.

[38] Quinn CE, Barisano A. Understanding, creating, and working with formulary systems. Am J Managed Care 1999; 5(10): 1311-7; quiz 1318-9.

[39] Giuliani G, Selke G, Garattini L. The German experience in reference pricing. Health Policy 1998; 44(1): 73-85.

[40] Busse R, Schreyogg J, Henke KD. Regulation of pharmaceutical markets in Germany: improving efficiency and controlling expenditures? Intl J Health Plann Manag 2005; 20(4): 329-49.

[41] Baines DL, Brigham P, Phillips DR, Tolley KH, Whynes DK. GP fundholding and prescribing in UK general practice: evidence from two rural, English Family Health Services Authorities. Public Health 1997; 111(5): 321-5.

[42] Dixon J, Glennerster H. What do we know about fundholding in general practice? BMJ 1995; 311(7007): 727-30.

[43] Braae R, McNee W, Moore D. Managing pharmaceutical expenditure while increasing access. The pharmaceutical management agency (PHARMAC) experience. PharmacoEconomics 1999; 16(6): 649-60

[44] Davis P. "Tough but fair"? The active management of the New Zealand drug benefits scheme by an independent Crown agency. Aust Health Rev 2004; 28(2): 171-81.

[45] Maynard A, Bloor K. Dilemmas in regulation of the market for pharmaceuticals. Health Aff (Millwood) 2003; 22(3): 31-41.

[46] Mossialos E, Oliver A. An overview of pharmaceutical policy in four countries: France, Germany, the Netherlands and the United Kingdom. Intl J Health Plann Manag 2005; 20(4): 291-306.

(C) Morgan et al.; Licensee Bentham Open.

This is an open access article licensed under the terms of the Creative Commons Attribution Non-Commercial License (http://creativecommons.org/licenses/by$\mathrm{nc} / 3.0 /$ )/ which permits unrestricted, non-commercial use, distribution and reproduction in any medium, provided the work is properly cited. 